\title{
Rearrangement of Thiodepsipeptides by $S \rightarrow N$ Acyl Shift Delivers Homodetic Autoinducing Peptides
}

\author{
Bengt H. Gless, ${ }^{a}$ Benjamin S. Bejder, ${ }^{a}$ Martin S. Bojer, ${ }^{\mathrm{b}}$ Hanne Ingmer, ${ }^{\mathrm{b}}$ and Christian A. Olsen*,a \\ ${ }^{a}$ Center for Biopharmaceuticals and Department of Drug Design and Pharmacology, Faculty of Health and Medical Sciences, \\ University of Copenhagen, Universitetsparken 2, DK-2100, Copenhagen, Denmark \\ bepartment of Veterinary and Animal Sciences, Faculty of Health and Medical Sciences, University of Copenhagen, \\ Stigbøjlen 4, DK-1870 Frederiksberg C, Denmark
}

Quorum sensing, autoinducing peptides, RiPPs, $S \rightarrow N$ acyl shift, cyclopeptides

\begin{abstract}
Group behavior in many bacteria relies on chemically induced communication called quorum sensing (QS), which plays important roles in regulation of colonization, biofilm formation, and virulence. In Gram-positive bacteria, QS is often mediated by cyclic ribosomally synthesized and posttranslationally modified peptides (RiPPs). In staphylococci for example, most of these socalled autoinducing peptides (AIPs) contain a conserved thiolactone functionality, which has been predicted to constitute a structural feature of AIPs from other species as well. Here, we show that pentameric AIPs from Lactobacillus plantarum, Clostridium perfringens, and Listeria monocytogenes that were previously presumed to be thiolactone-containing structures readily rearrange to become homodetic cyclopeptides. This finding has implications for the developing understanding of the cross-species communication of bacteria and may help guide the discovery of peptide ligands to perturb their function.
\end{abstract}

In bacteria, quorum sensing (QS) is a mechanism that relies on secretion and detection of a signaling molecules that modulate synchronized change in behavior of an entire bacterial population in a cell density-dependent manner. This cell-to-cell communication has been shown to regulate important functions, such as colonization, biofilm formation, and virulence. ${ }^{1}$ The accessory gene regulator (agr) locus is a group of four genes (agrBDCA) encoding the components of such a QS system found in several Gram-positive bacteria, ${ }^{2}$ including Listeria monocytogenes (Figure 1). ${ }^{3}$ The agr systems utilize short cyclic peptides, usually containing a thiolactione functionality, as QS signals. These so-called autoinducing peptides (AIPs) originate from the ribosomally synthesized AIP precursor peptide AgrD, which is intracellularly processed by the membrane-embedded protein AgrB. Outside the cell, the mature AIP binds the receptor protein $\mathrm{AgrC}$, which induces activation of the response regulator, AgrA. In turn, activated AgrA binds to the P2 promoter, resulting in upregulated expression of all agr genes, creating a positive-feedback loop. ${ }^{1,2}$ QS interference through inhibition of the AgrC receptor by foreign AIPs has been well established among staphylococci. ${ }^{4-7}$ Understanding this bacterial crosstalk may help elucidate complex social interactions that occur in mixed bacterial communities. Moreover, QS is linked to virulence in opportunistic pathogens like Staphylococcus aureus ${ }^{8}$ and Listeria monocytogenes ${ }^{9}$ and, consequently, inhibition of QS may offer an interesting therapeutic alternative to antibiotics for the treatment of infectious diseases caused by pathogenic bacteria. ${ }^{10}$ Thus, knowledge about AIP structures is crucial for probing the molecular mechanisms of QS and pharmacological aspects of QS inhibition. ${ }^{11}$ We recently developed a simple and robust procedure for enrichment of thiolactone-containing AIPs from complex bacterial supernatant, which facilitated the structural elucidation of a number of staphylococcal AIPs. ${ }^{12}$ This method is predicated on the chemoselective trapping of thiolactones by resin-bound cysteine residues through a native chemical ligation $(\mathrm{NCL})^{13}$ like transformation.

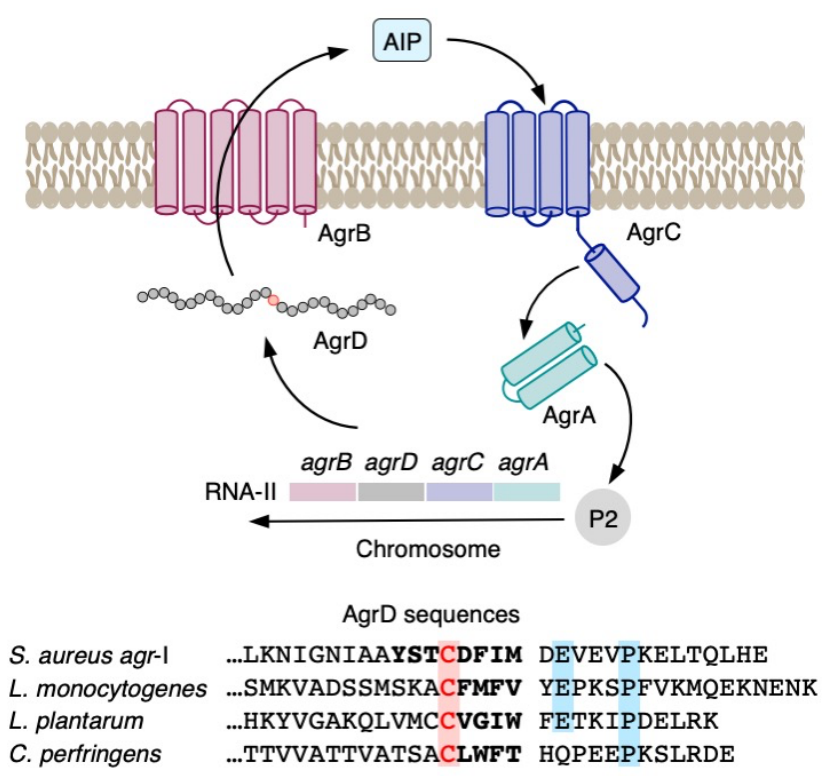

Figure 1. The agr QS system of L. monocytogenes and aligned AIP-precursor peptide sequences (AgrD) of Gram-positive bacteria with $a g r$ genes.

We attempted to identify the native AIP for L. monocytogenes, which had been reported as both a hexamer $(\mathbf{1})^{14}$ and a 
A. $\mathrm{pH}$-dependent $\mathrm{S} \rightarrow \mathrm{N}$ acyl shift of $\mathbf{2}$ to form $\mathbf{3}$

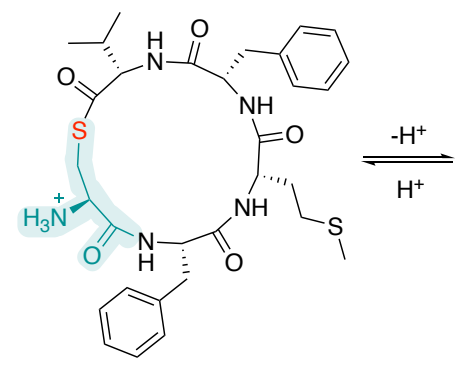

2

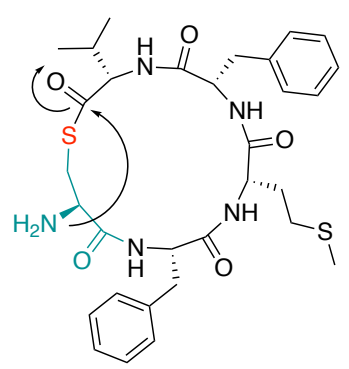

2

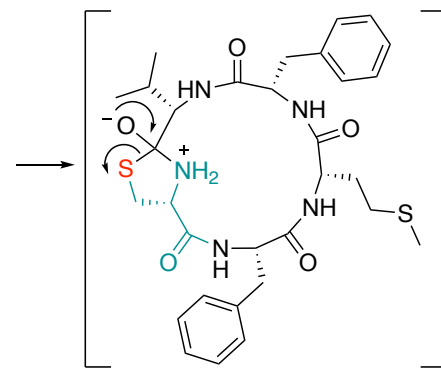

I

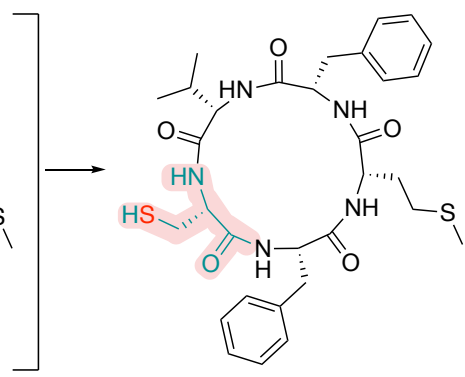

3

B. UPLC analysis of $\mathrm{S} \rightarrow \mathrm{N}$ acyl shift at $\mathrm{pH}=2-11$
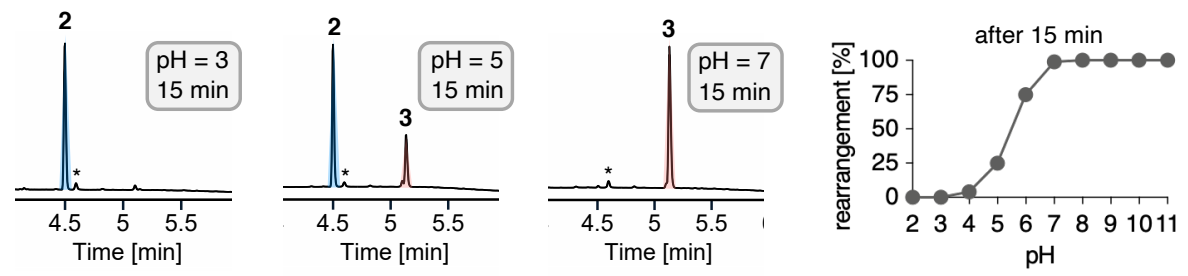

C. Estimation of $\mathrm{S} \rightarrow \mathrm{N}$ acyl shift rates

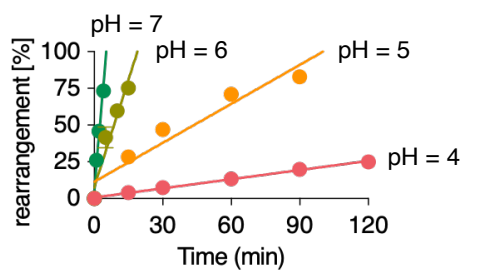

Figure 3. (A) Simplified mechanism of the $\mathrm{pH}$-dependent $\mathrm{S} \rightarrow \mathrm{N}$ acyl shift of $\mathbf{2}$ via the tetrahedral intermediate I. (B) UPLC-based assay to evaluate the $\mathrm{S} \rightarrow \mathrm{N}$ acyl shift of $\mathbf{2}$ at $\mathrm{pH} 2-11$. (C) Conversion rates of $\mathbf{2}$ to $\mathbf{3}$ were calculated based on zero order reaction kinetics form at least two experiments by the slope of [3]/t. $k$ values estimated for $\mathrm{pH}=4\left(k=0.208 \pm 0.006 \mathrm{M} \mathrm{s}^{-1}\right), \mathrm{pH}=5(k=0.88$ $\left.\pm 0.15 \mathrm{M} \mathrm{s}^{-1}\right), \mathrm{pH}=6\left(k=4.9 \pm 0.9 \mathrm{M} \mathrm{s}^{-1}\right)$, and $\mathrm{pH}=7\left(k=18 \pm 2 \mathrm{M} \mathrm{s}^{-1}\right)$.

A. Possible autoinducing peptides (AIPs) from Listeria monocytogenes

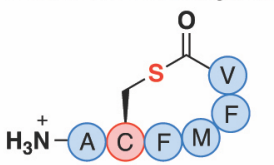

Lm-AIP 6-mer thioester (1)

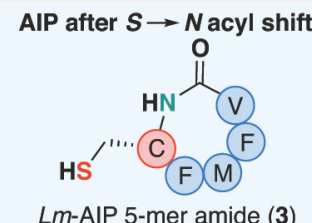

B. Reported exotail-free thiolactone AIPs from other Gram-positive bacteria<smiles></smiles>

L. plantarum AIP thioester (4)

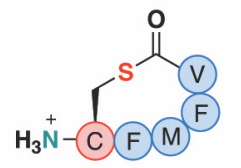

Lm-AIP 5-mer thioester (2)

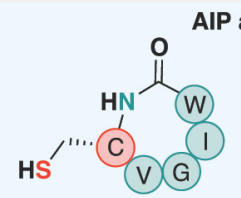

L. plantarum AIP (6)
AIP after $S \rightarrow N$ acyl shift

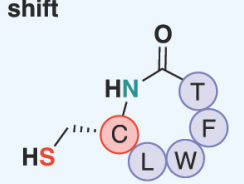

C. perfringens AIP (7)
Figure 2. Structures of (A) the proposed AIPs of L. monocytogenes and (B) the AIPs of L. plantarum and C. perfringens

pentamer (2) ${ }^{15}$ but failed to enrich any of the peptides from spent bacterial medium. ${ }^{12}$ This led us to speculate that a cyclic pentamer might be the native AIP, because such a thiolactone without a so-called exotail - would be expected to spontaneously undergo $\mathrm{S} \rightarrow \mathrm{N}$ acyl shift to produce a homodetic peptide (3; Figure 2 and $3 \mathrm{~A}$ ) that would be unreactive towards our cysteine resin. $^{12,16}$ Two other pentameric thiolactone-containing AIPs have been suggested in the literature, i.e., compound $\mathbf{4}$ from Lactobacillus plantarum ${ }^{17}$ and compound $\mathbf{5}$ from Clostridium perfringens $^{18}$ (Figure $2 \mathrm{~B}$ ), which we also predict to undergo the same rearrangement. Failure to identify these peptides by our trapping method (data not shown) provided further impetus for the idea that homodetic pentameric peptides might be the QS signaling molecules of certain bacteria. To investigate this hypothesis, we chose to focus on the pentamer peptide from $L$. monocytogenes. First, we synthesized the thiodepsipeptide 2 by solid-phase peptide synthesis (SPPS) and isolated it as a trifluoroacetic acid salt to prevent premature $\mathrm{S} \rightarrow \mathrm{N}$ shift. We also prepared the homodetic peptide $\mathbf{3}$ by our previously reported method utilizing cleavage-inducing cyclization followed by $\mathrm{S} \rightarrow \mathrm{N}$ shift (Supporting Scheme S1 and S2). ${ }^{19}$ Then, we designed a UPLC-based assay to monitor the conversion of 2 to 3 by intramolecular $\mathrm{S} \rightarrow \mathrm{N}$ acyl shift (Figure $3 \mathrm{~B}$ ). We first monitored the influence of $\mathrm{pH}$ on the rearrangement because the bacteria of interest inhabit different environments, where e.g., L. plantarum can stably grow under acidic conditions. We observed a strong effect of $\mathrm{pH}$ on the rate of the $\mathrm{S} \rightarrow \mathrm{N}$ acyl shift with no formation of $\mathbf{3}$ detected at low $\mathrm{pH}(\mathrm{pH} 2$ and 3). On the other hand, only 3 was observed after $15 \mathrm{~min}$ at $\mathrm{pH} \geq 7$. Interestingly, we did not observe competing hydrolysis of the thioester at the higher $\mathrm{pH}$ values. Next, we followed the $\mathrm{S} \rightarrow \mathrm{N}$ acyl shift of $\mathbf{2}$ over time at $\mathrm{pH} 4,5,6$, and 7 to assess if 2 would have a realistic lifetime to be the AIP used for cell-to-cell signaling at the given $\mathrm{pH}$ (Figure 3C). The rearrangement occurs slowly at $\mathrm{pH} 4$ with a rate constant of $0.2 \mathrm{M} \mathrm{s}^{-1}$ assuming that the $\mathrm{S} \rightarrow \mathrm{N}$ shift proceeds under zero order kinetics as well as no rate-determining proton transfer steps. The rate increases significantly with each $\mathrm{pH}$ unit, resulting in a $\sim 90$-fold faster reaction rate at $\mathrm{pH} 7 \mathrm{com}-$ pared to $\mathrm{pH}$ 4. Based on the same macrocycle size of $\mathbf{4}$ and $\mathbf{5}$ compared to 3 we predict that these peptides would also readily undergo $\mathrm{S} \rightarrow \mathrm{N}$ shift at neutral $\mathrm{pH}$. The initial report of $\mathbf{4}$ used a growth medium of $\mathrm{pH} 6.2$, but the $\mathrm{pH}$ prior to the identification 
by LC-MS was not reported. ${ }^{17}$ Thus, it cannot be excluded that lactic acid production might have lowered the $\mathrm{pH}$ to a level where 4 would be a prevalent species in these experiments. In the case of the studies employing synthetic $\mathbf{5}$ in neutral media, we are confident that the homodetic peptide 7 was the assayed molecule responsible for the agr related downstream effects reported. $^{18}$

A. Luminescent reporter strains assays for agr activity

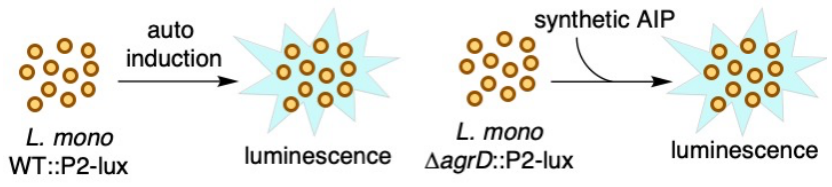

B. Assessment of agr activity of synthetic AIPs
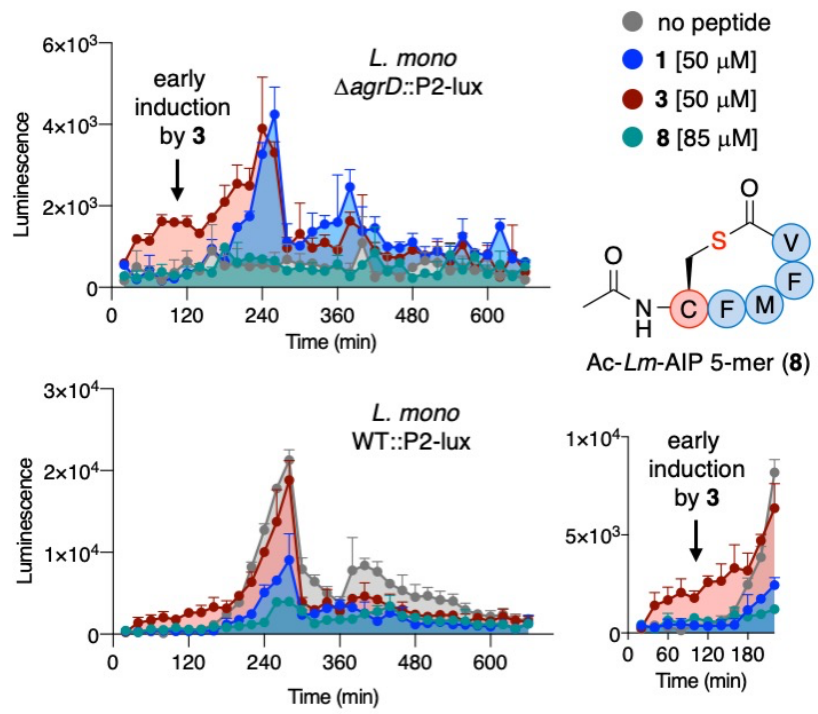

C. Influence of $\mathrm{pH}$ on growth and agr activity of WT::P2-lux
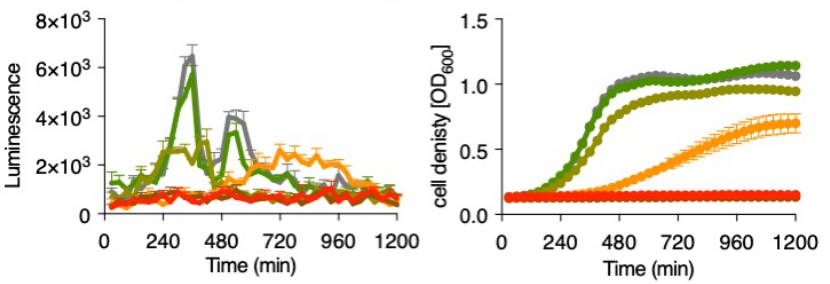

pH scale: $3 \bigcirc 4 \bigcirc 5 \bigcirc 6 \bigcirc 7 \bigcirc$ untreated $\mathrm{BH}$ medium

Figure 4. (A) Luciferase-expressing reporter strains of L. monocytogenes. (B) Representative experiment from treatment of lux-reporter strains with synthetic peptides showing early induction of the $a g r$ system by 3 . Further experiments can be found in the Supporting Information. Error bars are the standard of the error of the mean (SEM). (C) Growth and agr activity of WT::P2-lux reporter strain in $\mathrm{pH}-$ modified $\mathrm{BHI}$ media.

In the original identification of $\mathbf{2}$ by Zetzmann et al., a variety of synthetic peptides based on the AgrD peptide, including 1 and $\mathbf{2}$, were tested against luciferase-expressing L. monocytogenes reporter strains, one capable of producing AIPs (WT::P2lux) and one with the $\operatorname{agrD}$ gene deleted ( $\triangle a g r D:: \mathrm{P} 2-\mathrm{lux})$ and therefore incapable of AIP biosynthesis (Figure 4A). ${ }^{15}$ Based on the UPLC assays, compound $\mathbf{2}$ would be expected to undergo $\mathrm{S} \rightarrow \mathrm{N}$ acyl shift prior to the biological assay measurement, because the peptide was dissolved in phosphate-buffered saline (PBS, pH 7.4). To investigate this assumption, we treated the
$\operatorname{AagrD::P2-lux~mutant~strain~with~the~synthetic~peptides~} \mathbf{1}$ and $\mathbf{3}$ as well as an acetylated thiolactone version of $\mathbf{2}$, Ac- $\mathrm{Lm}$-AIP pentamer (8), which cannot undergo $\mathrm{S} \rightarrow \mathrm{N}$ acyl (Figure 4B). We were pleased to find that the homodetic peptide 3 resulted in the early induction of the agr system as would be expected for a native AIP, while the hexamer 1 led to a delayed increase in signal, which was also observed in previous work. ${ }^{15}$ Peptide 8 , on the other hand, had no effect on the reporter strain.

Next, we assayed the same compounds for the ability to induce luminescence in the WT::P2-lux reporter strain as well. Here the homodetic peptide $\mathbf{3}$ was again able to induce early

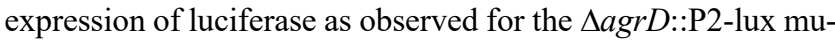
tant. In contrast, compounds $\mathbf{1}$ and $\mathbf{8}$ caused a significant decrease of the autoinduced signal appearing around the $4 \mathrm{~h}$ timepoint for untreated cultures (gray line). Thus, the previously proposed hexamer $(\mathbf{1})^{14}$ inhibits QS in the wild-type strain, strongly arguing against this molecule to be the natural AIP.

Our results using chemically synthesized $\mathbf{3}$ are in agreement with the reported observations by Zetzmann et al. when applying a buffered solution of thiolactone 2 . This strongly supports our initial prediction that the active molecule was also the homodetic peptide $\mathbf{3}$ and not the thiolactone $\mathbf{2}$ in the previous report. $^{15}$

The $\mathrm{S} \rightarrow \mathrm{N}$ shift of $\mathbf{2}$ is highly $\mathrm{pH}$-dependent and we therefore envisioned that growing the AIP-producing WT::P2-lux reporter strain in brain-heart-infusion (BHI) medium at different $\mathrm{pH}$ levels could result in an delay of agr activity since less of the activating homodetic peptide 3 would be available due to slower $\mathrm{S} \rightarrow \mathrm{N}$ acyl shift rearrangement (Figure $4 \mathrm{C}$ ). The bacteria were inoculated at $\mathrm{pH} 3-7$ but lower $\mathrm{pH}$ levels ( $\mathrm{pH} 3$ and 4) proved to be growth inhibitory and higher $\mathrm{pH}(\mathrm{pH} 5$ and 6) caused delays in growth to different extents. These results provide an additional line of evidence to suggest that $\mathbf{3}$ and not $\mathbf{2}$ is the native AIP of $L$. monocytogenes, because it is unlikely that the bacteria utilize a molecule that can only exist at $\mathrm{pH}$ levels that are not supporting growth of the organism.

In summary, we provide compelling evidence to suggest that the structures of AIPs previously believed to exist as thiolactones are actually cysteine-containing homodetic peptides in their functional state. The rearrangement of thiolactone-containing peptides without an exotail, to give their homodetic counterpart, happens spontaneously through intrinsic chemical reactivity in a $\mathrm{pH}$-dependent manner. Synthetically prepared homodetic pentamer peptide (3) furnished rapid induction of quorum sensing in luciferase reporter strains of L. monocytogenes with either wild-type agr system or agrD deleted, which strongly supports that this peptide is the AIP. Moreover, at lower $\mathrm{pH}$, where the thiolactone version of this sequence (2) remains stable, bacterial growth is arrested, further suggesting that $\mathbf{2}$ is unlikely to have an effect on QS. By extension, we argue that $L$. plantarum and $C$. perfringens are also highly likely to rely on homodetic cysteine-containing petamer peptides as their AIPs, i.e., compounds $\mathbf{6}$ and 7, respectively. Finally, the discovery of this mechanism in the bacterial synthesis of homodetic peptides is independently corroborated by Hertweck and coworkers, who show that hexameric thiolactones produced in clostridia undergo the same transformation by $\mathrm{S} \rightarrow \mathrm{N}$ acyl shift chemistry. ${ }^{20}$

This research provides fundamental insight into bacterial peptide biosynthesis and corrects the structures of previously assigned naturally occurring cyclic peptides. This discovery has implications for the future investigation of QS modulation and development of inhibitors of QS in a number of bacteria. 


\section{ASSOCIATED CONTENT}

\section{Supporting Information}

The Supporting Information is available free of charge.

Supplementary methods, schemes, figures and tables as well as copies of HPLC traces, ${ }^{1} \mathrm{H}$ and ${ }^{13} \mathrm{C}$ NMR spectra (PDF)

\section{AUTHOR INFORMATION}

\section{Corresponding Author}

*E-mail: cao@sund.ku.dk

\section{Funding Sources}

This work was supported by the Danish Independent Research Council-Natural Sciences (Grant No. 0135-00427B; C.A.O.) and the LEO Foundation Open Competition Grant (LF-OC-19000039; CAO).

\section{ACKNOWLEDGMENT}

We thank Prof. Christian Riedel (University of Ulm) for generously providing the bacterial strains used in the study.

\section{REFERENCES}

(1) Waters, C. M.; Bassler, B. L. QUORUM SENSING: Cell-toCell Communication in Bacteria. Annu. Rev. Cell Dev. Biol. 2005, 21, 319-346.

(2) Novick, R. P.; Geisinger, E. Quorum Sensing in Staphylococci. Annu. Rev. Genet. 2008, 42, 541-564.

(3) Autret, N.; Raynaud, C.; Dubail, I.; Berche, P.; Charbit, A. Identification of the agr locus of Listeria monocytogenes: role in bacterial virulence. Infect. Immun. 2003, 71, 4463-4471.

(4) Ji, G.; Beavis, R.; Novick, R. P. Bacterial Interference Caused by Autoinducing Peptide Variants. Science 1997, 276, 2027-2030.

(5) Otto, M.; Echner, H.; Voelter, W.; Götz, F. Pheromone CrossInhibition between Staphylococcus aureus and Staphylococcus epidermidis. Infect. Immun. 2001, 69, 1957-1960.

(6) Canovas, J.; Baldry, M.; Bojer, M. S.; Andersen, P. S.; Gless, B. H.; Grzeskowiak, P. K.; Stegger, M.; Damborg, P.; Olsen, C. A.; Ingmer, H. Cross-talk between Staphylococcus aureus and other staphylococcal species via the agr quorum sensing system. Front. Microbiol. 2016, 7, 1733.

(7) Paharik, A. E.; Parlet, C. P.; Chung, N.; Todd, D. A.; Rodriguez, E. I.; Van Dyke, M. J.; Cech, N. B.; Horswill, A. R. Coagulase-negative staphylococcal strain prevents Staphylococcus aureus colonization and skin infection by blocking quorum sensing. Cell Host Microbe $\mathbf{2 0 1 7}$ $22,1-11$.
(8) Wang, B.; Muir, T. W. Regulation of virulence in Staphylococcus aureus: molecular mechanisms and remaining puzzles. Cell Chem. Biol. 2016, 23, 214-224.

(9) Riedel, C. U.; Monk, I. R.; Casey, P. G.; Waidmann, M. S.; Gahan, C. G. M.; Hill, C. AgrD-dependent quorum sensing affects biofilm formation, invasion, virulence and global gene expression profiles in Listeria monocytogenes. Mol. Microbiol. 2009, 71, 11771189.

(10) Dickey, S. W.; Cheung, G. Y. C.; Otto, M. Different drugs for bad bugs: antivirulence strategies in the age of antibiotic resistance. Nat. Rev. Drug. Discov. 2017, 16, 457-471.

(11) McBrayer, D. N.; Cameron, C. D.; Tal-Gan, Y. Development and utilization of peptide-based quorum sensing modulators in Grampositive bacteria. Org. Biomol. Chem. 2020, 18, 7273-7290.

(12) Gless, B. H.; Bojer, M. S.; Peng, P.; Baldry, M.; Ingmer, H.; Olsen, C. A. Identification of autoinducing thiodepsipeptides from staphylococci enabled by native chemical ligation. Nat. Chem. 2019 $11,463-469$.

(13) Dawson, P. E.; Muir, T. W.; Clark-Lewis, I.; Kent, S. B. H. Synthesis of proteins by native chemical ligation. Science 1994, 266, 776-779.

(14) Todd, D. A.; Parlet, C. P.; Crosby, H. A.; Malone, C. L.; Heilmann, K. P.; Horswill, A. R.; Cech, N. B. Signal biosynthesis inhibition with ambuic acid as a strategy to target antibiotic-resistant infections. Antimicrob. Agents Chemother. 2017, 61, e00263-17.

(15) Zetzmann, M.; Sánchez-Kopper, A.; Waidmann, M. S.; Blombach, B.; Riedel, C. U. Identification of the agr peptide of Listeria monocytogenes. Front. Microbiol. 2016, 7, 989.

(16) Gless, B. H. PhD thesis, University of Copenhagen, 2019.

(17) Sturme, M. H. J.; Nakayama, J.; Molenaar, D.; Murakami, Y.; Kunugi, R.; Fujii, T.; Vaughan, E. E.; Kleerebezem, M.; de Vos, W. M. An agr-like two-component regulatory system in Lactobacillus plantarum Is involved in production of a novel cyclic peptide and regulation of adherence. J. Bacteriol. 2005, 187, 5224-5235.

(18) Ma, M.; Li, J.; McClane, B. A. Structure-Function Analysis of Peptide Signaling in the Clostridium perfringens Agr-Like Quorum Sensing System. J. Bacteriol. 2015, 197, 1807-1818.

(19) Gless, B. H.; Olsen, C. A. Direct Peptide Cyclization and OnePot Modification Using the MeDbz Linker. J. Org. Chem. 2018, 83, 10525-10534.

(20) Molloy, E. M.; Dell, M.; Haensch, V. G.; Dunbar, K. L.; Feldmann, R.; Oberheide, A.; Seyfarth, L.; Kumpfmüller, J.; Horch, T.; Arndt, H.-D.; Hertweck, C. Enzyme-Primed Native Chemical Ligation Produces Autoinducing Cyclopeptides in Clostridia. Angew. Chem. Int. Ed. 2021, DOI: $10.1002 /$ anie. 202016378 


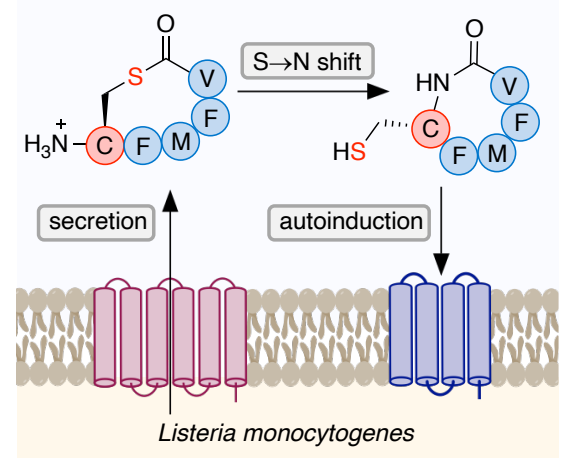

Cyclic autoinducing peptides, produced by Gram-positive bacteria for chemical communication through quorum sensing, were previously believed to contain thiolactone- or lactone functionalities. It has now been shown that this prediction is not always true. In examples where the biosynthesized thiolactone-containing peptide is void of a so-called exotail, spontaneous rearrangement produces its homodetic cyclopeptide counterpart. 